\title{
Changes in nocturnal insect communities in forest-dominated landscape relevant to artificial light intensity
}

\author{
Lee Hakbong ${ }^{1,2}$, Cho Yong-Chan ${ }^{1 *}$, Jung Sang-Woo ${ }^{3}$, Kim Yoon-Ho $^{3}$ and Lee Seung-Gyu ${ }^{4}$
}

\begin{abstract}
Background: Artificial light at night has recently been identified as a major factor adversely affecting global insect diversity. Here, we compared the insect diversity in Gwangneung Forest Biosphere Reserve, specifically in the Korea National Arboretum (with no artificial light at night), with that of three nearby urban sites with a gradient of artificial light at night (five locations at each site). We analyzed the effects of the artificial night lighting index, mean annual temperature, and field light intensity (lux) at night on the insect community structure.

Results: The urban sites generally exhibited higher species richness and abundance as well as clear indicator species compared with the control site. The size distribution of the collected insects markedly differed between the control and the three urban sites. The abundance of herbivorous and omnivorous insects increased and decreased, respectively, with the increase in light intensity. Species richness of herbivorous and omnivorous insects was likely correlated with the field light intensity at night and artificial night lighting index, respectively.

Conclusions: This study demonstrates the association between nighttime environment and marked changes in insect community structure and revealed consequent transition of ecosystem services by changes in trophic group composition.
\end{abstract}

Keywords: Artificial light at night, Biosphere reserve, Insect diversity, Protected area, Urbanization

\section{Background}

Insect species diversity and abundance are showing rapidly declining trends in all habitats (Hallmann et al. 2017). Although habitat loss, pollution, invasive species, and climate change have recently been identified as major drivers of the decline, the effect of artificial light at night (ALAN), which has never occurred before in evolutionary time scales, is relatively overlooked (Owens et al. 2020). ALAN, from streetlights, car headlights, and signs, is correlated with urban expansion (Elvidge et al. 2014) and is now widespread (Falchi et al. 2016; Davies and Smyth 2018). Approximately 90\% of Europe and $50 \%$ of the USA are exposed to various light sources at

\footnotetext{
* Correspondence: bz0288@korea.kr

${ }^{1}$ Restoration Center for Endangered Species, National Institute of Ecology, Yeongyang 36531, South Korea

Full list of author information is available at the end of the article
}

night (Falchi et al. 2016). In Korea, the ratio of land area exposed to light pollution is the second largest in the world, and the geographical and social characteristics of small land area, urbanization, and high-density population are the main causes of light pollution (Government of Korea 2018). Furthermore, approximately $60 \%$ of invertebrate species worldwide are active at nighttime (Hölker et al. 2010). Thus, ALAN can affect not only the biological traits of these species, such as physiology (Eisenbeis and Hänel 2009), behavior (Yoon et al. 2010; Russo et al. 2019), and reproduction (Witherington 1992; Mbugua et al. 2020) but also their ecological communities (Davies et al. 2012). However, because of a bias toward studies on diurnal species, the effect of ALAN on whole ecological communities remains relatively less extensively studied (Sanders and Gaston 2018; Owens et al. 2020).

(c) The Author(s). 2021 Open Access This article is licensed under a Creative Commons Attribution 4.0 International License, which permits use, sharing, adaptation, distribution and reproduction in any medium or format, as long as you give appropriate credit to the original author(s) and the source, provide a link to the Creative Commons licence, and indicate if changes were made. The images or other third party material in this article are included in the article's Creative Commons licence, unless indicated otherwise in a credit line to the material. If material is not included in the article's Creative Commons licence and your intended use is not permitted by statutory regulation or exceeds the permitted use, you will need to obtain permission directly from the copyright holder. To view a copy of this licence, visit http://creativecommons.org/licenses/by/4.0/. 
Despite the lack of strong evidence demonstrating the ecological effect of ALAN on invertebrates, some recent studies have reported changes in insect communities due to ALAN (Davies et al. 2012; Holzhauer et al. 2015; Spoelstra et al. 2015; Plummer et al. 2016; De Medeiros et al. 2016; Sanders et al. 2018; Firebaugh and Haynes 2020). For example, ALAN has affected the composition of arthropod communities, leading to increases in the abundance of predatory and scavenging arthropods (Davies et al. 2012). Holzhauer et al. (2015) reported that specific groups of insects [e.g., beetles (Coleoptera), flies (Diptera), and bugs (Hemiptera)] were more abundant at sites with artificial light than in those without artificial light and that such sites were characterized by high insect abundance compared with those without artificial light. Plummer et al. (2016) and De Medeiros et al. (2016) demonstrated that radiations from ultraviolet light at night attracted large numbers of moths (Lepidoptera) and beetles (Coleoptera), respectively, likely reducing insect diversity. Furthermore, Sanders et al. (2018) showed that ALAN increased the density of aphids, changing the food web structure.

In contrast to studies reporting changes in insect communities due to ALAN, there were also studies that reported no effective change due to ALAN. For example, moth communities sensitive to light were not influenced by ALAN (Spoelstra et al. 2015). Firebaugh and Haynes (2020) monitored changes in an arthropod community under ALAN for 2 years, and they did not observe any effect of ALAN on the abundance of herbivores or predators. Studies reporting the effect of ALAN on insect communities were generally conducted by controlled experiment by installation of artificial light sources; thus, field experiments in real-world situation were needed.

The present study was conducted in Gwangneung Forest Biosphere Reserve, one of the major areas for biodiversity protection in South Korea. The reserve consists of an area without artificial lighting (Korea National Arboretum) and several urbanized and light-polluted areas. The Korea National Arboretum has not contained ALAN since the 1990s, although the night light conditions in areas adjacent to the arboretum have changed considerably over the past few decades. This environmental gradient has been maintained across Gwangneung Forest Biosphere Reserve for a long time, and therefore, the insect communities present in these areas reflect the ecological effects of ALAN as well as urbanization on insect communities over the last few decades.

In the present study, we identified the ecological effect of ALAN on insect communities in Gwangneung Forest Biosphere Reserve including a control site (no ALAN) and three nearby sites along a gradient of development situations (DS). We aimed to determine the following:
(1) how insect species richness and abundance and indicator species differ along the gradient of sites; (2) which of the potential environmental factors [e.g., temperature, artificial night lighting index (ANLI), and field light intensity] cause differences in the community structure of nocturnal insects in the study area; (3) how distribution of insect body size differs along the gradient of sites; (4) how the composition of trophic groups differs along the gradient of sites; and (5) which factors significantly affect changes in the composition of trophic groups.

\section{Materials and methods \\ Study area}

We conducted field surveys in Gwangneung Forest Biosphere Reserve in June and August 2017. The mean annual temperature and precipitation for this area were $12.2^{\circ} \mathrm{C}$ and $1387.9 \mathrm{~mm}$, respectively (Cho et al. 2020).

\section{Site description}

We selected the exhibition garden in the Korea National Arboretum as a control site, and three urban sites with different DS, namely, Neungnae Village (DS1), Jikdong Samgeori (DS2), and Gwangneungnae (DS3) (Fig. 1). The area of each site was $100 \mathrm{ha}$. The distance from the center of the control site to the nearest light source (convenience store) is $1 \mathrm{~km}$, and the streetlight on the road where cars sometimes travel is $600 \mathrm{~m}$. The other three sites received diverse levels of ALAN from various sources, such as streetlights, shops, residential areas, and vehicular traffic. The DS1 site was surrounded by a forest and included commercial and residential buildings with some two-way, two-lane roads and streetlights. There was no artificial lighting on the roads outside the DS1 site. The DS2 site was surrounded by residential buildings as well as many lodging establishments and shops that were well lit at night. The DS3 site was located in an urban area with a complex road network and densely packed apartment complexes and commercial facilities.

We measured the ANLI and mean annual air temperature $\left({ }^{\circ} \mathrm{C}\right)$ at each site. The ANLI was calculated by dividing the area occupied by shops and residential buildings, including streetlights and roads, by the total area, based on high-resolution satellite images from ArcGIS 10.3. ANLI ranged from 0 to 100 , where 0 indicated no ALAN and 100 indicated the maximum levels of ALAN. For example, if there is a 100-ha area composed of $30 \%$ of vegetation with no light and $70 \%$ of commercial areas and roads, ANLI is calculated as 30. ANLI as simple index is equal to vegetation area in the specific area. We applied simple approach because it is very difficult to quantify ALAN (e.g., type and amount of artificial light at night) in complex urban situation. To incorporate temperature changes during industrialization of this 


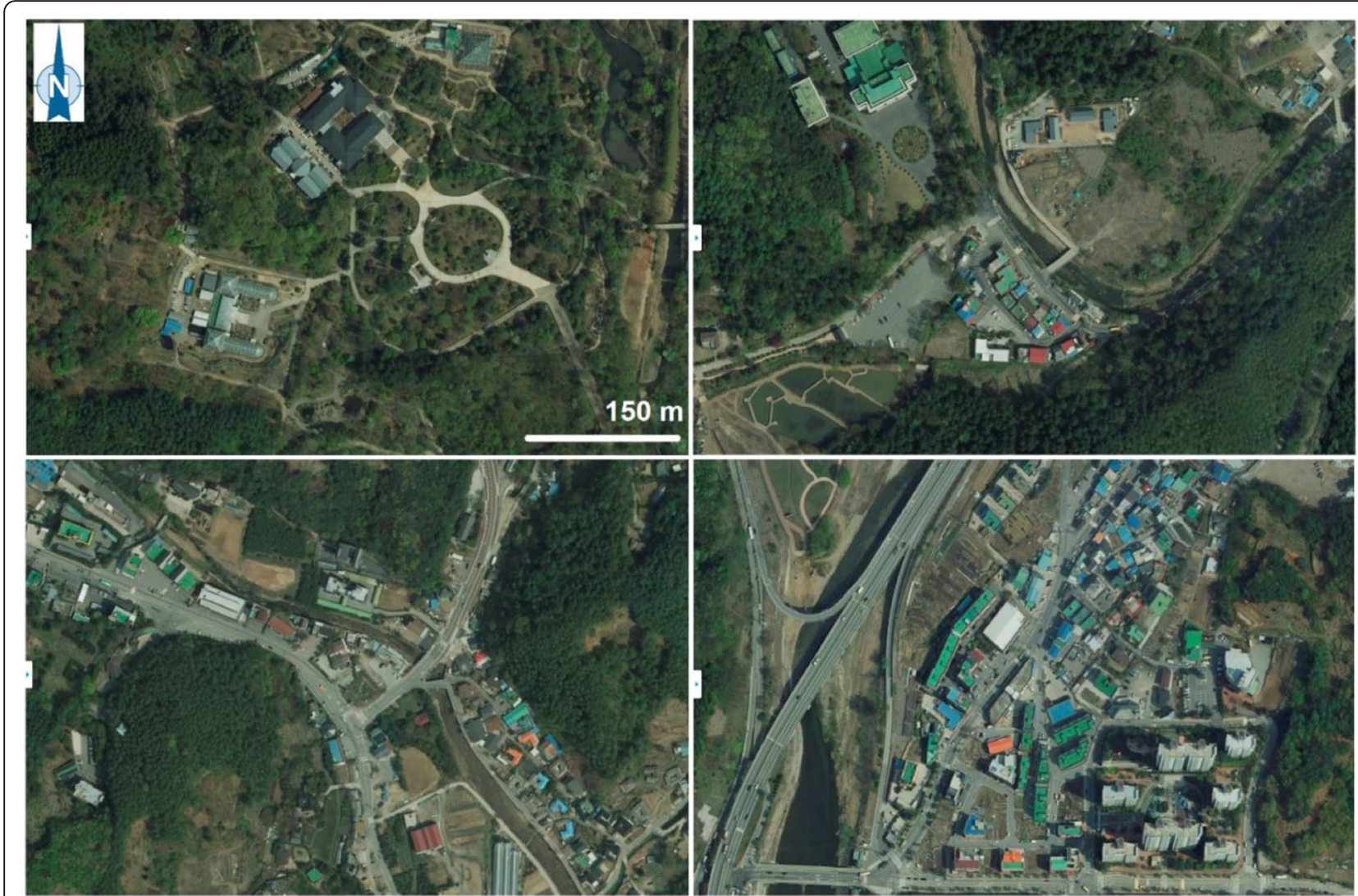

Fig. 1 Aerial photographs of the study sites in Gwangneung Forest Biosphere Reserve. A the Korea National Arboretum, where there is no artificial light at night (control). B Neungnae Village, where there are two-lane roads, shops, and residential houses (DS1). C Jikdong Samgeori, where there is a three-way intersection with two-lane roads, shops, and residential houses (DS2). D Gwangneung, where there are numerous two-lane roads, shops, and residential houses, including apartment complexes (DS3)

area, we determined the mean annual air temperature in the southern Korean peninsula between 1970 and 2014, using the map of mean annual air temperatures (Arc/ Info binary grid), which is stored at the Korea National Arboretum. This was applied to each site. We also measured the field light intensity (lux) at night using a light meter (LX-1332, Custom Corp., Tokyo, Japan) at 50 locations at each site (100 ha) divided into 100 grid cells. We randomly selected 50 grid cells to measure lux using the random-number generator in Excel 2016.

\section{Insect collection}

At each study site, insects were collected along roads and at the edges of commercial areas where plants such as Rhododendron spp. and Buxus microphylla var. koreana were found. These sites have different levels of human activity and consumption of plants by insects. Two nighttime surveys of insects were conducted in 2017, i.e., before (June) and after (August) the rainy season. Each survey was conducted on the same day of the month $\left(8^{\text {th }}\right)$ in the lunar calendar between 21:00 and 23:00, to account for natural nighttime light conditions and insect activity. For each site, we conducted three round trips of five belt transects $(5 \times 20 \mathrm{~m})$ and collected insects using a sweep net (diameter $45 \mathrm{~cm}$ ) to assess species richness and abundance. Insect abundance data across the two seasons (before and after the rainy season) were pooled for analysis.

\section{Insect species richness and abundance and indicator species along the gradient of sites}

To identify differences in insect species richness and abundance along the gradient of sites, we identified the proportional richness and abundance of insect orders at each site. Then, we used Venn diagrams ( $R$ package "VennDiagram") (Chen and Boutros 2011) to illustrate the proportion of shared and unique insect species at the sites. Finally, we quantitatively compared insect species richness and abundance at the sites.

\section{Differences in insect community composition}

Based on the insect abundance data at each site, we determined the patterns of turnover in insect communities and determined the factors that contributed most to the 
changes. Meta-non-parametric multidimensional scaling was performed using the R package "vegan" (Oksanen et al. 2019) to explore the turnover patterns. Of the environmental factors (i.e., ANLI, mean annual air temperature, and field light intensity), those that best explained the changes with high predictability $(p<0.001)$ were exclusively displayed.

\section{Size class distribution by site}

We referred to information from online databases (e.g., Korea Biodiversity Information System) for data on the size of the collected insects. Except for earwigs (Dermaptera), we defined insect body size as the distance from the front of the head to the tip of the abdomen. The distance from the front of the head to the base of the forceps was measured for determining the body size of earwigs. We also analyzed patterns in the collected insects for abundance distribution by size class and checked the differences in the abundance distribution compared to the control site, using the two-sample Kolmogorov-Smirnov test.

\section{Insect trophic structure by site}

We classified the collected insects according to the trophic groups (i.e., herbivore, carnivore, omnivore, and detritivore). The classification was based on the investigators' knowledge and discussions, plus information from online databases (i.e., Korea Biodiversity Information System, daum.net, naver.com, and google.com).

\section{Statistical analysis}

The mean annual air temperature and field light intensity for each site and the species richness and abundance data for the collected insects were not normally distributed, so the differences in data between the sites were analyzed using the rank-based non-parametric KruskalWallis test followed by a Bonferroni post hoc test. Bonferroni correction ( $\alpha=0.05 /$ number of tests) was considered to avoid type I errors. All statistical analyses were conducted in R software ( $\mathrm{R}$ Core team 2019). Data are expressed as means \pm standard deviations.

\section{Results}

\section{ANLI, temperature, and light intensity}

Overall, the ANLI and field light intensity at the study sites increased with increasing development. The ANLI was the highest in DS3 (56.5), followed by DS2 (30.5), DS1 (17.1), and the control had an ANLI of zero (Table 1). The urban site DS2 (median: $11.80{ }^{\circ} \mathrm{C}$ ) had the highest mean annual air temperature, followed by DS3 $\left(11.58{ }^{\circ} \mathrm{C}\right)$, the control $\left(11.36^{\circ} \mathrm{C}\right)$, and DS1 $\left(11.28^{\circ} \mathrm{C}\right)$. However, these differences were not statistically significant. Field light intensity differed significantly among the sites $\left(\chi^{2}=125.48, \mathrm{df}=\right.$ $3, p=0.001)$ and was the highest in DS2 (12.2 lux),
Table 1 Summary of artificial night lighting index, mean annual air temperature, and field light intensity (lux) at the survey sites

\begin{tabular}{llll}
\hline Study sites & ANLI & Temperature $\left({ }^{\circ} \mathbf{C}\right)$ & Field light intensity (lux) \\
\hline Control & 0.0 & 11.36 & $0.0^{\mathrm{a}}$ \\
DS1 & 17.1 & 11.28 & $5.2^{\mathrm{b}}$ \\
DS2 & 30.5 & 11.80 & $12.2^{\mathrm{c}}$ \\
DS3 & 56.5 & 11.58 & $8.7^{\mathrm{bc}}$ \\
\hline
\end{tabular}

$A N L I$, artificial night lighting index; DS1, development situations at Neungnae Village; DS2, development situations at Jikdong Samgeori; DS3, development situations at Gwangneungnae

No mean was calculated for the ANLI. Differences in mean annual air temperature between the survey areas are not statistically significant, and the values are expressed as medians. Different letters in field light intensity values indicate significant differences ( $n=50$ per site). Refer to Fig. 1 for site descriptions and locations

followed by DS3 (8.7 lux), DS1 (5.2 lux), and the control (0 lux). Field light intensity showed considerable variance depending on the distance from the light sources, such as vehicular traffic and especially streetlights.

\section{Proportional insect species richness and abundance of insect orders by site}

The Gwangneung Forest Biosphere Reserve has long maintained the gradient of DS. The control site and three nearby sites (DS1, DS2, and DS3) showed notable differences in proportional insect species richness and abundance (Fig. 2; Supplementary Table S1). This was especially evident with the proportion of hemipteran species increasing along the gradient of DS (Fig. 2). Neuropteran species were collected only from urban sites (DS1, DS2, and DS3), while dermapteran species were unique to the control site.

In the control site, the five orders of Hemiptera (23.2\%), Hymenoptera (20.3\%), Orthoptera (18.8\%), Coleoptera (17.4\%), and Diptera (11.6\%) accounted for 91.3\% of the total collected species, with relatively equal proportions (Fig. 2A). In contrast, the proportion of Hemiptera increased at the urban sites (DS1 vs. DS2 vs. DS3 $=24.4 \%$ vs. $39.0 \%$ vs. $44.4 \%$ ), and that of Coleoptera decreased (DS1 vs. DS2 vs. DS3 $=30.5 \%$ vs. $23.7 \%$ vs. 22.2\%; Fig. 2A).

Although the five orders [Hemiptera (17.4\%), Hymenoptera (20.2\%), Orthoptera (18.3\%), Coleoptera (21.1\%), and Diptera $(15.6 \%)]$ had similar proportions of abundance (Fig. 2B), an uneven distribution of the insect orders was observed at the urban sites. Unlike the control site, hemipteran species at the urban sites accounted for more than half of total insect abundance (DS1 $=55.6 \%$, DS2 $=64.6 \%$, DS3 = 64.2\%; Fig. $2 \mathrm{~A}$ ).

The number of insect species common to the control and urban sites was markedly lower than that common to the urban sites only (3vs. 16, Fig. 3). The only three species common to the control and urban sites were Metcalfa pruinosa, Monolepta shirozui, and 


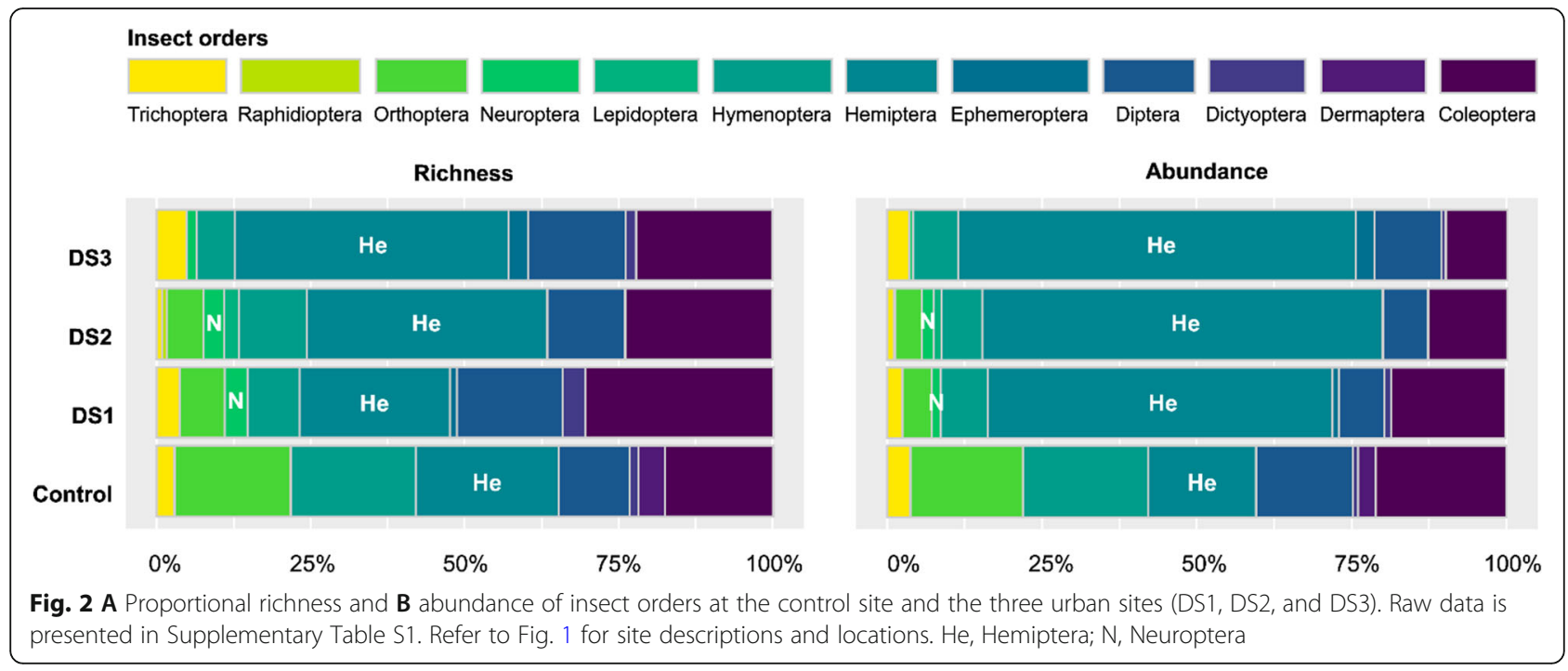

Pristomyrmex pungens, and the number of species unique to the control, DS1, DS2, and DS3 sites was 33, 22,48 , and 15, respectively (Fig. 3).

Site conditions significantly affected insect abundance ( $H=12.177, \mathrm{df}=3, p=0.007)$, but not species richness $(H=7.649$, df $=3, p=0.054)$ (Fig. 4). Pairwise comparisons of species abundance between the sites revealed that it was not significant $(p>0.008)$. However, DS2 showed the highest maximum species richness and abundance (C vs. DS1 vs. DS2 vs. DS3 = 39 vs. 92 vs. 101 vs. 50), and the control site showed the lowest minimum species abundance $(\mathrm{C}$ vs. DS1 vs. DS2 vs. DS3 = 16 vs. 29 vs. 49 vs. 25) (Fig. 4).
Insect community composition and size distribution

When the differences in species composition at each study site were analyzed by rank, the NMDS1 differentiated the control site and three urban sites (DS1-3), and their spatial distribution was significantly correlated with ANLI $\left(r^{2}=0.582, p=0.002\right)$ (Fig. 5).

By applying the two-sample Kolmogorov-Smirnov test between the control site and each of the three urban sites (DS1, DS2, and DS3), we confirmed significant differences in the size class distribution of insects (controlDS1: Kolmogorov-Smirnov $(\mathrm{KS})=0.12, p<0.0001$; control-DS2: $\mathrm{KS}=0.17, p<0.0001$; control-DS3: $\mathrm{KS}=$ $0.12, p<0.0001$ ) (Fig. 6). Compared to the control site,

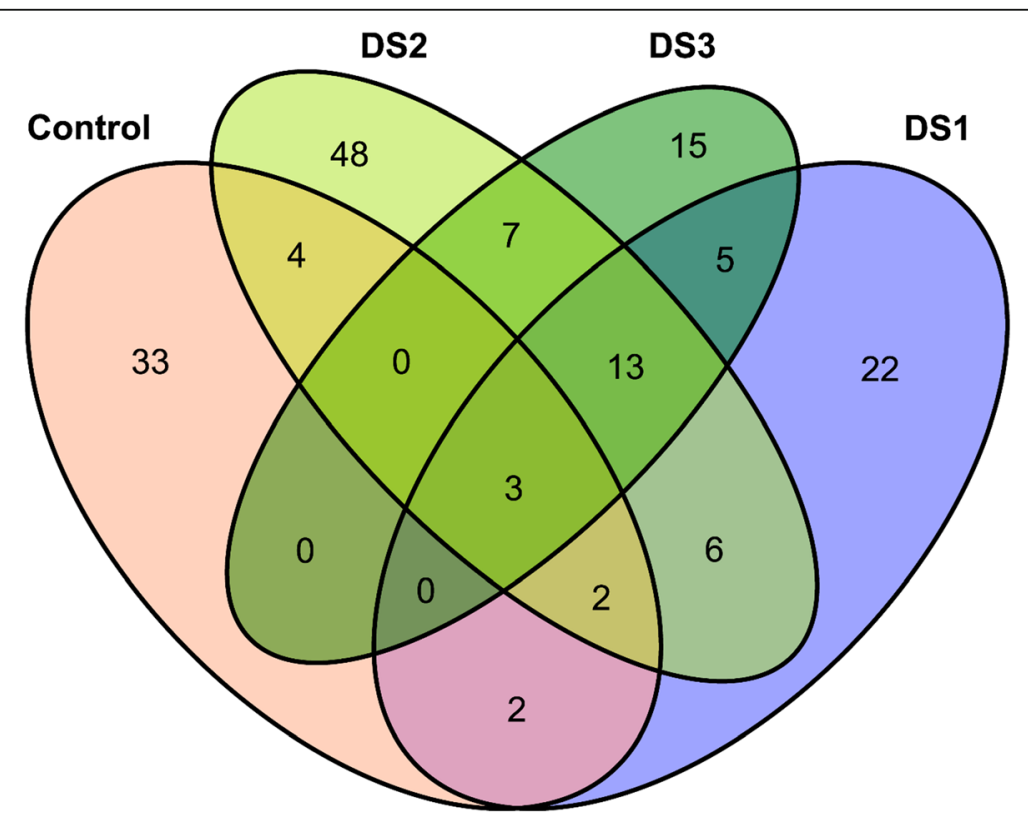

Fig. 3 Venn diagram showing groups of insect species shared between study sites (control, DS1, DS2, and DS3). Refer to Fig. 1 for site descriptions and locations 


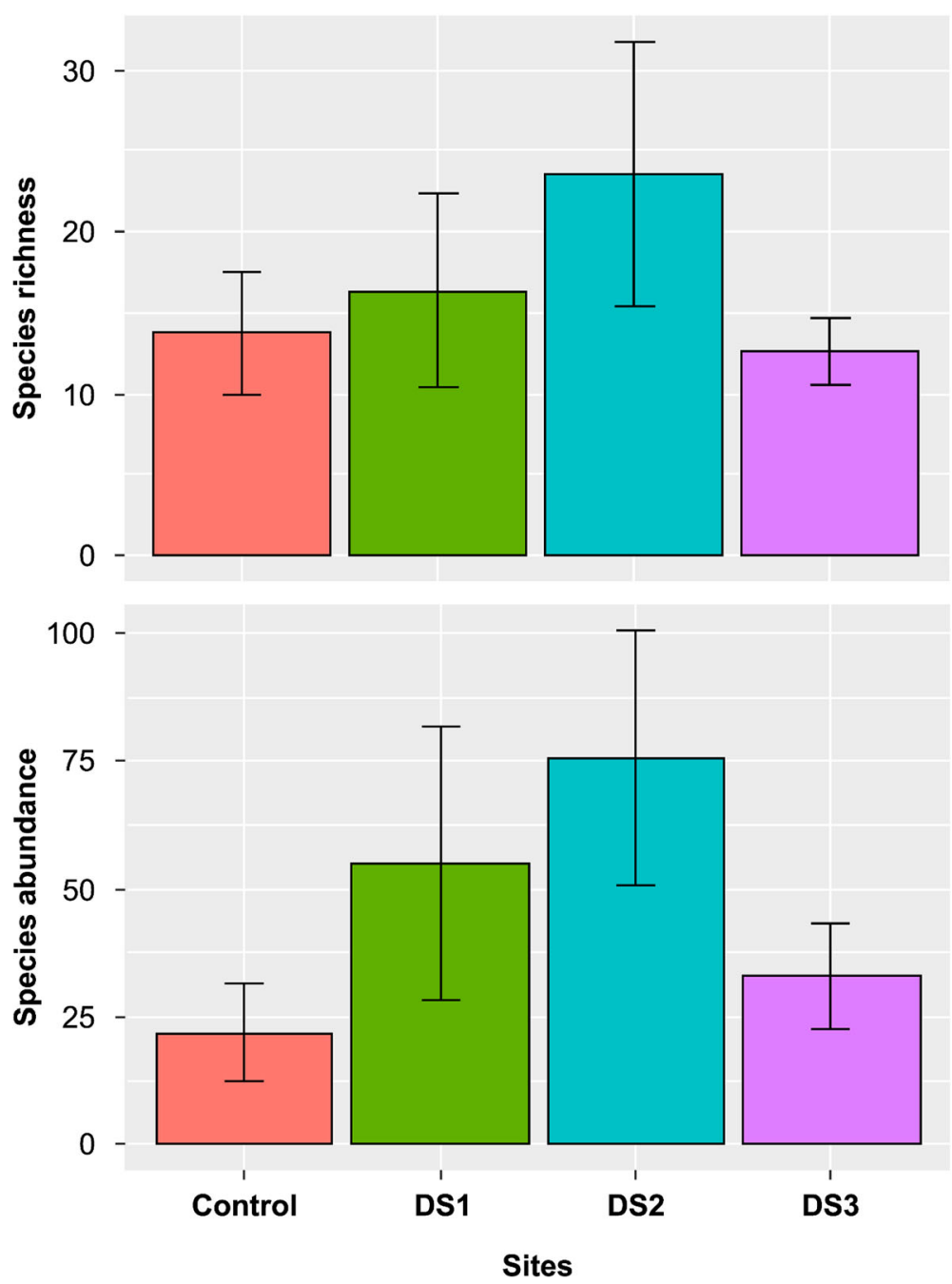

Fig. 4 A Differences in insect species richness and $\mathbf{B}$ abundance among the four study sites (control, DS1, DS2, and DS3). Refer to Fig. 1 for site descriptions and locations. Bars and error bars indicate mean \pm standard deviations, and pairwise comparisons of richness and abundance between the sites are not statistically significant by Bonferroni correction $(p>0.008)$

the urban sites showed considerably increased numbers of small insects $(\leq 15 \mathrm{~mm})$. In particular, the control site showed a reverse-J-shaped distribution of insect sizes, but the three urban sites showed right-skewed unimodal distributions (Fig. 6).

\section{Insect trophic structure along the sites}

The collected insects were divided into four trophic groups (herbivores, omnivores, carnivores, detritivores), and the median and proportional species richness and abundance of these groups were compared (Fig. 7). Of the four trophic groups, only herbivores (richness: $H=$ 7.944, $\mathrm{df}=3, p=0.047$, abundance: $H=13.316, \mathrm{df}=3$, $p=0.004$ ) and omnivores (richness: $H=13.428, \mathrm{df}=3$, $p=0.004$, abundance: $H=10.895, \mathrm{df}=3, p=0.012$ ) showed significant differences in species richness and abundance between study sites (Fig. 7A). However, pairwise comparisons between study sites were not significant for the two trophic groups. The proportional species richness and abundance of herbivores were approximately $54 \%$ and higher at the urban sites with ALAN, compared with those at the control site. The proportion of omnivores at the urban sites was lower than that of the control site, and in DS3 specifically, which was experiencing the highest development pressure, no omnivores were observed (Fig. 7).

\section{Discussion}

The direct relationship between the effect of ALAN on insects and urban expansion (Elvidge et al. 2014) is implicated in a reduction in insect diversity (Owens et al., 2020); however, community-based studies in real-world ecosystems are limited. We demonstrated that ALAN affected the insect community structure (species diversity, 


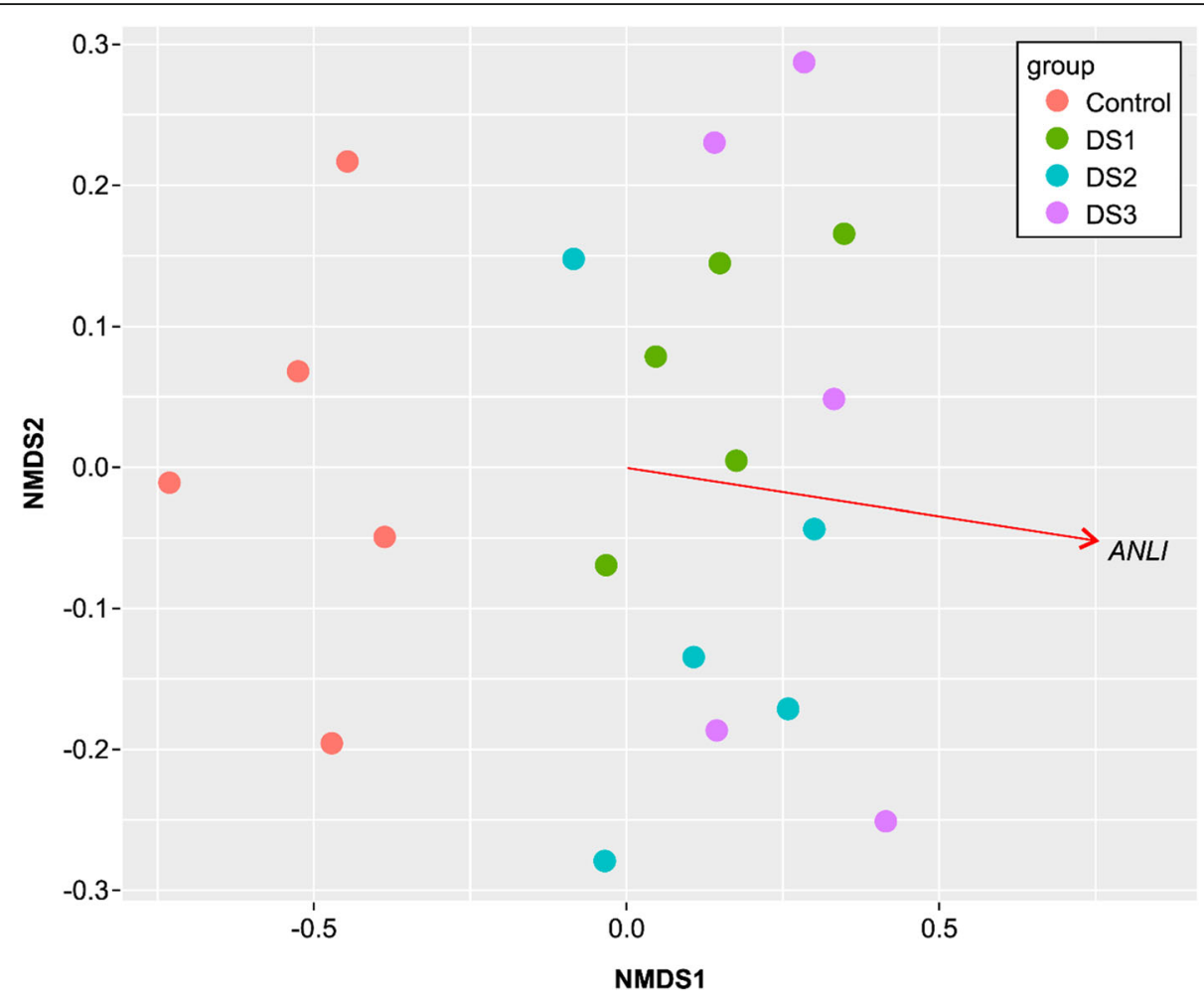

Fig. 5 Results of meta-NMDS ordination using abundance data for communities of insects collected from each study site (control, DS1, DS2, and DS3). Refer to Fig. 1 for site descriptions and locations. A significant correlation between insect communities and environmental factors (ANLI, temperature, lux) was only observed for ANLI $\left(r^{2}=0.582, p=0.002\right)$

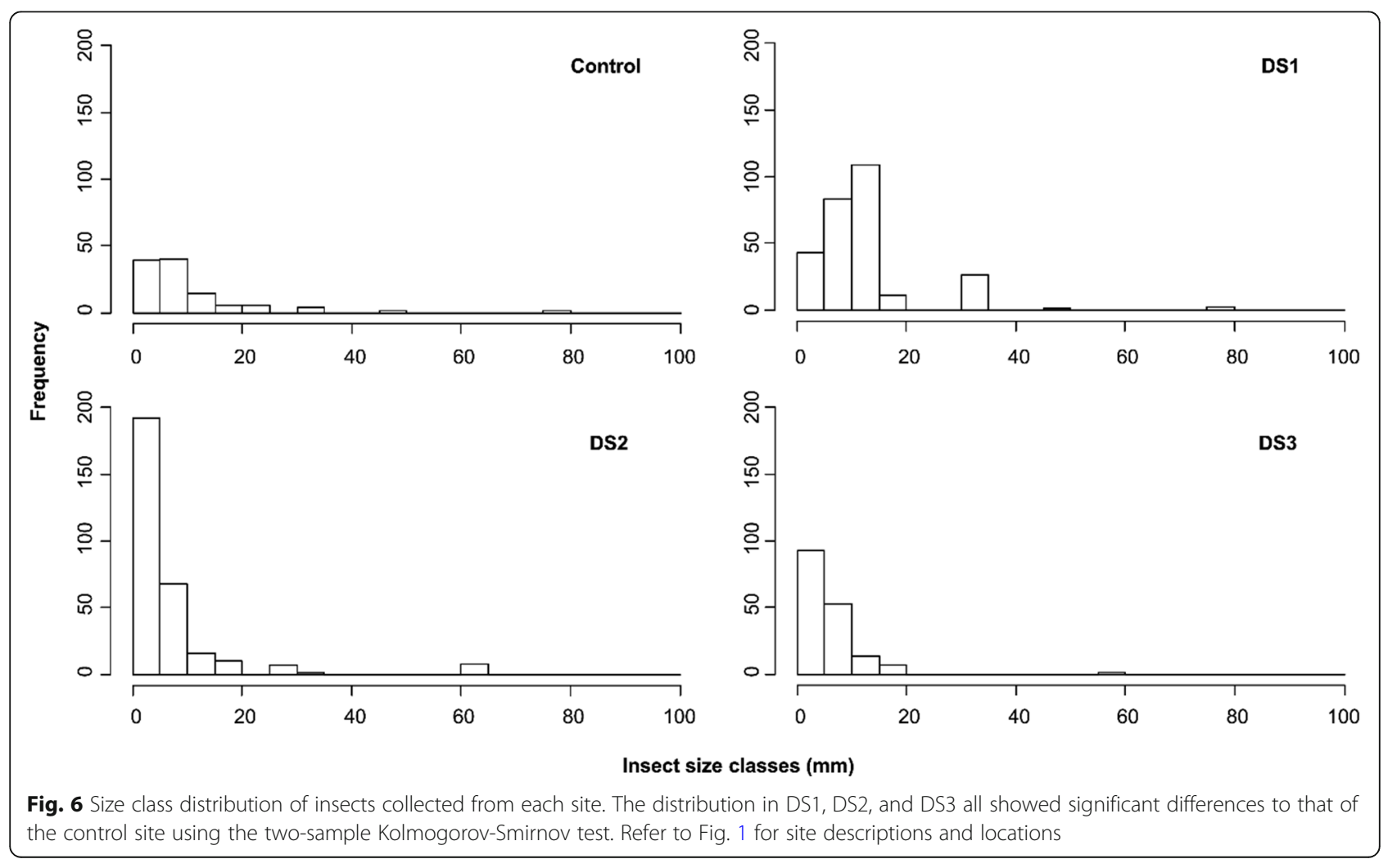



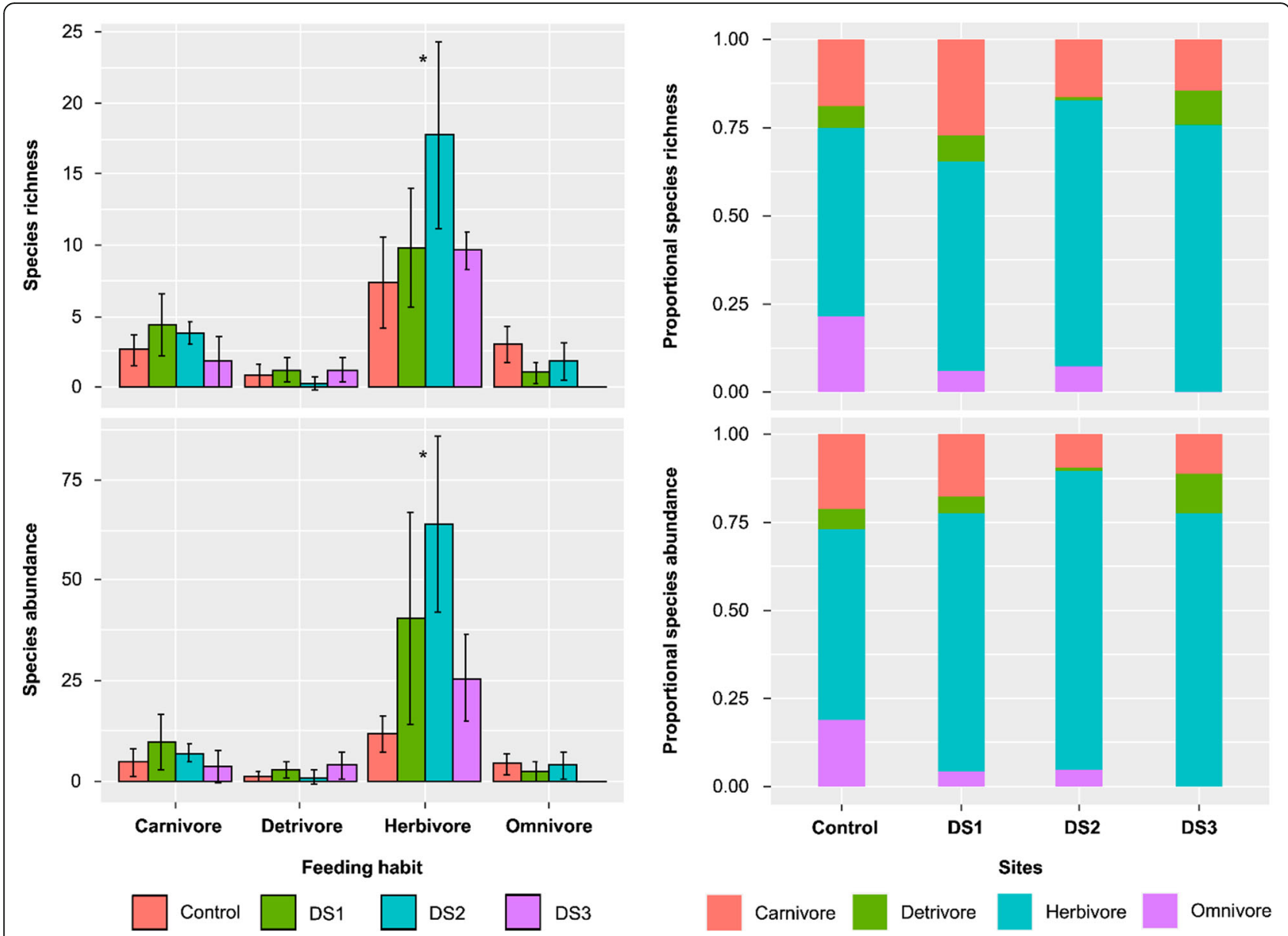

Fig. 7 A Differences in insect species richness and $\mathbf{B}$ the abundance between the study sites for each trophic group and $\mathbf{C}$ proportional richness and $\mathbf{D}$ the abundance by trophic group between study sites. Asterisks indicate significant differences $(p<0.05)$. The results of multiple pairwise comparisons between the study sites were not significant ( $\mathbf{A}$ and $\mathbf{C})$. The error bars represent standard deviation. Site descriptions and locations are presented in Fig. 1

size distribution, and trophic level) in Gwangneung Forest Biosphere Reserve, where a constant light regime has been maintained at night for the last few decades. We considered one dark site and the nearby three sites with a gradient of ALAN. Specifically, the insect communities showed an over-dominance of small insects $(\leq 15 \mathrm{~mm})$ and herbivore groups, related to an increasing gradient of DS and ALAN intensity.

Unlike previous studies that manipulated ALAN (Davies et al. 2012; Holzhauer et al. 2015; Spoelstra et al. 2015; Plummer et al. 2016; De Medeiros et al. 2016; Sanders et al. 2018; Firebaugh and Haynes 2020), the present study provides evidence that the change of night light environment results in the compositional change of nighttime collected insect communities in real-world ecosystems. The three urban sites with ALAN (DS1-3) showed higher heterogeneity in nocturnal insect species composition than the control site, and this was correlated with ANLI, an index of artificial light.
Research on insect size class distribution is limited. In the present study, the distribution of the size classes under natural nighttime conditions showed a reverse-J shape. Unlike the control site, a marked increase in the number of small insects at nighttime in developed environments resulted in a unimodal distribution. Biometric variables, such as dry mass and length, are closely related to ecological functions (Hallmann et al. 2017). The change in size classes revealed in the present study may potentially be related to changes in species composition and function in groups. In studies on insect communities, it is important to determine the values of variables such as organism size (e.g., biomass) and evaluate their correlations with other structures and functional elements (Shortall et al. 2009). In addition, more attention should be paid to the body size distribution in order to understand the relationships between structural attributes and habitat types, such as urban, agricultural, and remote areas (Chown and Gaston 2010). 
The large increase in the herbivore population at the three urban sites was the result of reduced overall predation pressure due to lower numbers of omnivores. This increase in herbivore numbers could be attributed to their attraction to nitrogen- and phosphorus-rich food (leaves), which is a commonly reported limiting factor for insects in urban environments (Moreira et al. 2019). The reduction in omnivores was the main factor responsible for the simplification of the food web. Omnivores, which comprise approximately 40 families in 12 orders, have generally adapted to supplemental nutrition that is lacking in a plant-based diet and are an important element in natural and agricultural ecosystems (Krimmel 2011). Because omnivores perform the roles of both herbivores and carnivores within the food web, they can consistently alter the intensity and direction (top-down or bottom-up) of trophic cascades. In the present study, it is likely that the three urban sites contained highquality edible leaves. In these areas, the increased abundance and richness of herbivores may lead to increased spatial competition between herbivores and omnivores and thus affect the extent to which omnivorous insects could enter the area. Moreover, with regard to omnivore-herbivore-plant interactions, the presence of high-quality plant-based food reduces predatory behavior, rather than increasing the attraction for omnivores. This reduction, in turn, is beneficial to herbivores (Eubanks and Denno 2000). Omnivores can also enhance top-down control by pressuring predator groups, but this pattern was not observed in the present study. Future studies that assess the effects of high-quality plant resources on competition between herbivores and omnivores may provide important insights into the food web changes associated with urbanization.

Although many studies have reported nighttime urban light pollution using satellite images (Elvidge et al. 2007; Sutton et al. 2007; Gaston et al. 2015), the impact on biodiversity at the community level has not been fully clarified. However, it is an extremely challenging task to understand the effects of nighttime light on biological communities in urban environments because of the diversity and interconnectedness of factors within urban nighttime environments. In the present study, we used ANLI, mean annual air temperature, and field light intensity at the survey sites as the factors characterizing the urban nighttime environment. However, this approach and these factors are not sufficient to explain the causal relationships between ALAN and the observed changes in the insect communities clearly.

\section{Abbreviations}

ALAN: Artificial light at night; ANLl: Artificial night lighting index; C: Control; DS: Development situation; Meta-NMDS: Meta-non-parametric multidimensional scaling

\section{Supplementary Information}

The online version contains supplementary material available at https://doi. org/10.1186/s41610-021-00207-9.

Additional file 1:. Supplementary Table S1.

Acknowledgements

We thank Kim Han-Gyul and Jung Songhie for data preparation and sincerely thank Professor Lim Jongok for providing pertinent information on the trophic groups of the collected insects.

\section{Authors' contributions}

LH and CYC designed the study; LSW, KYH, and LSG carried out field sampling and performed the analysis; and LH and CYC wrote the manuscript. The authors read and approved the final manuscript.

\section{Funding}

This research was supported by the Research Program (KNA1-2-17, 13-3, KNA1-2-26, 16-4, and KNA1-2-32, 18-3) of the Korea National Arboretum.

Availability of data and materials

The datasets generated and/or analyzed during the current study are available from the corresponding author upon reasonable request.

\section{Declarations}

Ethics approval and consent to participate

Not applicable.

\section{Consent for publication}

Not applicable.

\section{Competing interests}

The authors declare that they have no competing interests.

\section{Author details}

${ }^{1}$ Restoration Center for Endangered Species, National Institute of Ecology, Yeongyang 36531, South Korea. ${ }^{2}$ Conservation Center for Gwangneung Forest, Korea National Arboretum, 509, Gwangneungsumogwon-ro, Soheul-eup, Pocheon 11186, South Korea. ${ }^{3}$ DASARI Research Institute of BioResources, Daejeon 34127, South Korea. ${ }^{4}$ Animal Resources Division, National Institute of Biological Resources, Incheon 22689, South Korea.

Received: 19 October 2021 Accepted: 11 November 2021

Published online: 22 November 2021

\section{References}

Chen H, Boutros PC. VennDiagram: a package for the generation of highlycustomizable Venn and Euler diagrams in R. BMC Bioinform. 2011;12(1):35. https://doi.org/10.1186/1471-2105-12-35.

Cho YC, Kim H-G, Kim JS, Lee H, Jung SH, Lee DH, et al. 2019 annual report on Gwangneung forest and experimental forest. Seoul: Sumeungil; 2020.

Chown SL, Gaston KJ. Body size variation in insects: a macroecological perspective. Biol Rev. 2010;85(1):139-69. https://doi.org/10.1111/j.1469-185X.2009.00097.x.

Davies TW, Bennie J, Gaston KJ. Street lighting changes the composition of invertebrate communities. Biol Lett. 2012;8(5):764-7. https://doi.org/10.1098/rsbl.2012.0216.

Davies TW, Smyth T. Why artificial light at night should be a focus for global change research in the 21st century. Glob Chang Biol. 2018;24(3):872-82. https://doi.org/10.1111/gcb.13927.

de Medeiros BAS, Barghini A, Vanin SA. Streetlights attract a broad array of beetle species. Rev Bras Entomol. 2016;61(1):74-9. https://doi.org/10.1016/.r.be.2016.11.004.

Eisenbeis $G$, Hänel A. Light pollution and the impact of artificial night lighting on insects. In McDonnell MJ, Hahs AH, Breuste JH, editors. Ecology of cities and towns. Cambridge. Cambridge University Press, 2009. p. 243-263.

Elvidge CD, Safran J, Tuttle B, Sutton P, Cinzano P, Pettit D, et al. Potential for global mapping of development via a nightsat mission. GeoJournal. 2007; 69(1-2):45-53. https://doi.org/10.1007/s10708-007-9104-x.

Elvidge CD, Sutton PC, Baugh K, Ziskin DC, Ghosh T, Anderson S. National trends in satellite observed lighting: 1992-2009. In: Weng Q, editor. Global urban monitoring and assessment through earth observation. Boca Raton, Florida: CRC Press; 2014. 
Eubanks M, Denno RF. Host plants mediate omnivore-herbivore interactions and influence prey suppression. Ecology. 2000;81:936-47.

Falchi F, Cinzano P, Duriscoe D, Kyba CCM, Elvidge CD, Baugh K, et al. The new world atlas of artificial night sky brightness. Sci Adv. 2016;2(6):e1600377. https://doi.org/10.1126/sciadv.1600377.

Firebaugh A, Haynes K. Multi-year experiment shows no impact of artificial light at night on arthropod trophic structure or abundance. Ecosphere. 2020;11(8): e03227. https://doi.org/10.1002/ecs2.3227.

Gaston KJ, Visser ME, Hölker F. The biological impacts of artificial light at night: the research challenge. Philos Trans R Soc Lond B. 2015;370(1667):20140133. https://doi.org/10.1098/rstb.2014.0133.

Government of Korea. National plan for prevent light pollution (2019-2023). Sejong: Ministry of Environment; 2018.

Hallmann CA, Sorg M, Jongejans E, Siepel H, Hofland N, Schwan H, et al. More than 75 percent decline over 27 years in total flying insect biomass in protected areas. PLoS One. 2017;12(10):e0185809. https://doi.org/10.1371/ journal.pone.0185809.

Hölker F, Moss T, Griefahn B, Kloas W, Voigt CC, Henckel D, et al. The dark side of light: a transdisciplinary research agenda for light pollution policy. Ecol Soc. 2010;15(4). https://doi.org/10.5751/ES-03685-150413.

Holzhauer SIJ, Franke S, Kyba CCM, Manfrin A, Klenke R, Voigt CC, et al. Out of the dark: establishing a large-scale field experiment to assess the effects of artificial light at night on species and food webs. Sustainability. 2015;7(11): 15593-616. https://doi.org/10.3390/su71115593.

Krimmel BA. Omnivorous insects: evolution and ecology in natural and agricultural ecosystems. Nature Education Knowledge. 2011;3(10):52.

Mbugua SW, Wong CH, Ratnayeke S. Effects of artificial light on the larvae of the firefly Lamprigera sp. in an urban city park, peninsular Malaysia. J Asia Pac Entomol. 2020;23(1):82-5. https://doi.org/10.1016/j.aspen.2019.10.005.

Moreira X, Abdala-Roberts L, Berny Mier y Teran JC, Covelo F, de la Mata R, Francisco $\mathrm{M}$, et al. Impacts of urbanization on insect herbivory and plant defences in oak trees. Oikos. 2019;128(1):113-23. https://doi.org/10.1111/oik.05497.

Oksanen J, Blanchet FG, Friendly M, Kindt R, Legendre P, McGlinn D, Minchin PR, O'Hara RB, Simpson GL, Solymos P, Stevens MHH, Szoecs E, Wagner H. vegan: Community Ecology Package. R package version 25-6. 2019.

Owens ACS, Cochard P, Durrant J, Farnworth B, Perkin EK, Seymoure B. Light pollution is a driver of insect declines. Biol Conserv. 2020;241:108259. https:// doi.org/10.1016/j.biocon.2019.108259.

Plummer KE, Hale JD, O'Callaghan MJ, Sadler JP, Siriwardena GM. Investigating the impact of street lighting changes on garden moth communities. J Urban Ecol. 2016;2(1):1-10. https://doi.org/10.1093/jue/juw004.

$\mathrm{R}$ Core Team. R: A language and environment for statistical computing. Vienna, Austria: R Foundation for Statistical Computing; 2019.

Russo D, Ancillotto L, Cistrone L, Libralato N, Domer A, Cohen S, et al. Effects of artificial illumination on drinking bats: a field test in forest and desert habitats. Anim Conserv. 2019;22(2):124-33. https://doi.org/10.1111/acv.12443.

Sanders D, Gaston KJ. How ecological communities respond to artificial light at night. J Exp Zool A Ecol Integr Physiol. 2018;329(8-9):394-400. https://doi. org/10.1002/jez.2157.

Sanders D, Kehoe R, Cruse D, van Veen FJF, Gaston KJ. Low levels of artificial light at night strengthen top-down control in insect food web. Curr Biol. 2018; 28(15):2474-8e2473. https://doi.org/10.1016/j.cub.2018.05.078.

Shortall CR, Moore A, Smith E, Hall MJ, Woiwod IP, Harrington R. Long-term changes in the abundance of flying insects. Insect Conservation Diversity. 2009;2(4):251-60. https://doi.org/10.1111/j.1752-4598.2009.00062.x.

Spoelstra K, van Grunsven RHA, Donners M, Gienapp P, Huigens ME, Slaterus R, et al. Experimental illumination of natural habitat - an experimental set-up to assess the direct and indirect ecological consequences of artificial light of different spectral composition. Philos Trans R Soc Lond B. 2015;370(1667): 20140129. https://doi.org/10.1098/rstb.2014.0129.

Sutton PC, Elvidge CD, Ghosh T. Estimation of gross domestic product at sub-national scales using nighttime satellite imagery. Int J Ecol Econ Stat. 2007;8:5-21.

Witherington BE. Behavioral responses of nesting sea turtles to artificial lighting. Herpetologica. 1992;48:31-9.

Yoon T, Kim DG, Kim S, Jo S-I, Bae Y, et al. Aquat Insects. 2010;32:195-203.

\section{Publisher's Note}

Springer Nature remains neutral with regard to jurisdictional claims in published maps and institutional affiliations.

Ready to submit your research? Choose BMC and benefit from:

- fast, convenient online submission

- thorough peer review by experienced researchers in your field

- rapid publication on acceptance

- support for research data, including large and complex data types

- gold Open Access which fosters wider collaboration and increased citations

- maximum visibility for your research: over $100 \mathrm{M}$ website views per year

At BMC, research is always in progress.

Learn more biomedcentral.com/submissions 